\title{
Visual feedback explains why propointing is better than antipointing in spatial neglect
}

\author{
Kathrin S. Utz ${ }^{a}$, Constanze Hesse ${ }^{b}$, Annika Hintz ${ }^{a}$, Daniela Grüneberger ${ }^{a}$, Hartwig \\ Kulke $^{c}$, Inga Roth ${ }^{d}$, Thomas Klos ${ }^{d}$, Vaclav Kromichal ${ }^{d}$, Arthur Melms ${ }^{a}$, Wilfried \\ Schupp $^{c}$, Detlef Kohld, and Thomas Schenk ${ }^{\mathrm{e} *}$ \\ a Department of Neurology, Friedrich-Alexander University Erlangen-Nuremberg, Germany \\ b School of Psychology, University of Aberdeen, Aberdeen, United Kingdom \\ ${ }^{\mathrm{C}}$ Centre for Neurorehabilitation, Fachklinik Herzogenaurach, Germany \\ ${ }^{d}$ Department of Neurological Rehabilitation, Klinikum am Europakanal, Erlangen, Germany \\ e Department of Psychology, Ludwig-Maximilians-University Munich, Germany
}

${ }^{*}$ Corresponding author:

Thomas Schenk, Ludwig-Maximilians University, Munich

Department of Psychology, Leopoldstr. 13

80802 Munich, Germany

Email:Thomas.schenk@psy.Imu.de

Phone: +49 89 2180-3123, Fax: +49 (0) 892180 - 63738 


\section{Abstract}

Rossit et al. (2011) showed that neglect patients perform normally in a propointing task but not in an antipointing task which requires pointing towards the mirrored position of a target. It is assumed that antipointing relies on information from the perceptual pathway of our visual brain. Therefore, this finding supports the notion that neglect is a disorder that primarily affects perceptual spatial representations within the brain leaving spatial maps used for visuomotor guidance intact. Alternatively, performance of patients might be compromised in both tasks, but only obviously so in tasks in which online corrections are made more difficult. It can be argued that online-corrections via visual feedback are less effective in antipointing because a direct comparison between hand and target is not possible in this condition. Secondly, it is also known that neglect patients have a pronounced egocentric bias which is assumed to be associated with a deviation of the perceived body midline. Since the midline is used to compute the end-position in the antipointing task this could also explain why patients are worse in antipointing. We investigated the influence of visual feedback on pro- and antipointing and the effect of providing a visual reference line for the antipointing task in right-brain damaged patients with neglect $(n=20)$, right-brain damaged patients without neglect $(n=23)$ and in a group of healthy participants $(n=22)$. The withdrawal of visual feedback had a stronger effect on propointing compared to antipointing. This effect was stronger in neglect patients than in patients without neglect or healthy controls. The introduction of a reference line reduced errors in antipointing performance, particularly in neglect patients with a strong egocentric bias. The results support our alternative account and challenge the hypothesis that the spatial disorder in neglect affects primarily perceptual maps within the visual system. 
Key words: visuomotor control; allocentric; egocentric; pointing; antipointing 


\section{Introduction}

As a matter of fact, patients suffering from spatial neglect show typical perceptual spatial biases, such as omissions of targets located on the side opposite to the side of the brain lesion, or ipsilesional deviations when judging the centre of horizontal lines (Heilman, Valenstein, \& Watson, 2000; Kerkhoff, 2001). However, does this lateral bias also become manifest in visually guided actions? This issue has been debated during the nineteen-nineties and again in the mid 2000's (for review see Harvey \& Rossit, 2012). Reaching and grasping towards the contralesional hemispace was found to be slower (Mattingley, Husain, Rorden, Kennard, \& Driver, 1998), right-ward directional errors were observed for pointing toward targets or pointing midway between two targets (Goodale, Milner, Jakobson, \& Carey, 1990; Harvey, Milner, \& Roberts, 1994; Jackson, Newport, Husain, Harvey, \& Hindle, 2000) and curved hand paths during reaching were reported (Jackson et al., 2000). However, other studies did not find any neglect-specific bias in visuomotor tasks (Harvey et al., 2001; Himmelbach \& Karnath, 2003; Himmelbach, Karnath, \& Perenin, 2007; Karnath, Dick, \& Konczak, 1997; Konczak \& Karnath, 1998).

Himmelbach and colleagues (2007) pointed out that those studies which found visuomotor deficits compared neglect patients with healthy individuals but not with braindamaged patients without neglect. Thus the visuomotor deficits are possibly a consequence of brain damage per se and not an indication of a neglect-specific bias (Himmelbach et al., 2007).

The perception action model formulated by Milner and Goodale (Milner \& Goodale, $1995,2006)$ offers a plausible explanation of the seeming paradox of impaired visualperceptual, but intact visuomotor behaviour in neglect patients. Milner and Goodale 
postulate two anatomical distinct streams within the brain serving different functions. The ventral stream, running from the primary visual cortex to the occipital-temporal cortex, mainly uses stable allocentric (object-related) and consciously accessible representations for visuospatial perception. In contrast, the dorsal stream projecting from the primary visual cortex to the occipital-parietal cortex uses short-lived egocentric (body-related) and consciously inaccessible representations for online motor control. In their book "The visual brain in action" (Milner and Goodale, 1995, 2006), Milner and Goodale raise the question of how the neglect disorder and the anatomical structures involved in this disorder fit into their scheme. Traditionally, neglect has been described as a disorder of the right parietal lobe (Heilman, Valenstein, \& Watson, 2000) and thus anatomically it seems tempting to associate the disorder with the dorsal stream. Moreover, neglect is typically characterized as a disorder of space perception and as such appears to be a deficit that functionally can neither be exclusively assigned to the perceptual (ventral) nor to the visuomotor (dorsal) system. Milner and Goodale (2006) criticise both of these notions. With respect to the anatomical status of the brain structures involved in neglect they point to the fact that these brain structures form a distributed network including structures in the superior temporal, inferior parietal, frontal regions and also subcortical nuclei. Furthermore, the parietal lesions typically associated with neglect are found in the inferior parietal lobule and not the superior parietal regions considered to form the dorsal system. Based on anatomical considerations the critical regions seem to fall outside both the ventral and dorsal visual system. However, in functional terms, Milner and Goodale (1995) argue that the temporo-parietal areas, typically damaged in neglect patients, may be part of a high-level, multimodal representational system that is neither part of the ventral nor dorsal system but receives 
its visual information from the ventral system. In support of this hypothesis they provide two arguments. Firstly, they reject the idea that there is one unified representation of space. In their view, the visual brain maintains a number of distinct spatial maps with different coordinate origins and different metrics. Those spatial maps are designed and optimized for different behavioural functions, reside in anatomically distinct regions of the brain, and will only be recruited when those behavioural functions are called for. Milner and Goodale emphasize in particular the distinction between perceptual and visuomotor functions that call for different spatial maps (Milner and Goodale, 1995). Consequently, there is not one single representation of space, but several. It is to be expected that brain damage leading to a visuospatial deficit (as in the case of neglect) will create a disorder that affects only one type of spatial representation. They argue that in the case of neglect the disorder affects primarily the type of spatial representation used for conscious, perceptual processes. For example, it is known that neglect is most prominent when an explicit perceptual judgement is called for (e.g. line bisection). It has also been demonstrated that neglect can affect the mental representation of space (Bisiach and Luzzatti, 1978) and thus seems to directly influence visual awareness. Moreover, neglect errors are often object-centred, i.e. the left of a house will be neglected even if that house is presented in the patient's right hemispace. In contrast, sensory information from the patient's otherwise neglected left hemispace will often still influence behavioural responses (such as emotional judgements, e.g. Driver \& Vuilleumier, 2001; Marshall \& Halligan, 1988) that do not require the explicit acknowledgment of the left-sided information. Furthermore, as noted before, visuomotor responses, such as pointing or reaching do not seem to be affected by the neglect disorder. This link between automaticity, visuomotor control and spared behaviour was 
illustrated in a study by Mclntosh and colleagues (McIntosh, McClements, Dijkerman, Birchall, \& Milner, 2004). They compared two tasks: a bisection task which required an explicit judgement of the midpoint between two objects and an obstacle avoidance task. In the obstacle-avoidance task, participants were asked to reach between two objects without colliding with them; no explicit judgment of the midpoint between the two potential obstacles was required. McIntosh and colleagues (2004) found that for neglect patients, the influence of the left-located object was diminished but only for the bisection task. Obstacle avoidance behaviour seems to be largely automatic and independent of the conscious perception of the obstacles itself (see Mclntosh et al., 2004; Striemer, Chapman \& Goodale, 2009, but see also: Hesse et al., this issue). This suggests that automatic, visuomotor behaviour is not affected by the spatial disorder found in unilateral neglect. It might thus be argued that the spatial disorder in neglect affects primarily the maps involved in perception and spares the maps used for the automatic guidance of visuomotor behaviour. As such, neglect deficits can be expected to primarily impact tasks and functions that are linked to the ventral visual system.

This characterisation of neglect allows not only to account for the apparent contrast between perceptual deficits and preserved visuomotor behaviour but presents an opportunity to predict more specifically which behaviour should be affected by neglectlike symptoms and which behaviour will remain unaffected. The basis of such predictions is formed by the list of criteria used by the perception-action model to characterize the behavioural functions of the perceptual, i.e. ventral, visual system. An important criterion is the directness of the relationship between the spatial position of the visual target and required end-position of a behavioural response (Milner and Goodale, 2008). If those two positions are aligned, the behaviour is direct, can rely on body- 
related coordinates and will thus be served by the visuomotor system. If the two positions are dissociated the behaviour is indirect, relies on an object- or scene-centred spatial reference-system and will therefore depend on input from the perceptual ventral system. An example for such a ventrally driven task in which visual target and behavioural end-position are dissociated is antipointing (Marai and Heath, 2010). Antipointing requires participants to point towards the mirrored position of a target in the opposite side of space. Thus, neglect patients whose disorder affects spatial representations that rely on input from the ventral system, should be impaired in antipointing, but not in normal propointing ${ }^{1}$. In fact, this prediction has been verified in a study by Rossit et al. (2011). They investigated propointing and antipointing in eleven right-brain-damaged patients with left-sided neglect, ten right-brain-damaged patients without neglect and ten healthy individuals. All participants could see the target and their hand during the entire trial. Rossit and colleagues (2011) examined the pointing performance using both directional (signed) and non-directional (unsigned) errors. Neglect patients were more impaired than both control groups when directional errors were analysed. This difference was, however, independent of the task or the hemifield in which the target was presented. The more interesting finding was obtained for unsigned errors: only in the case of antipointing did neglect patients perform worse than the two control groups. This finding conformed to the pattern predicted by the perception-action model. Specifically, the results, confirmed the idea that antipointing relies more on ventral-stream input than propointing. This finding also bolstered the claim that the

\footnotetext{
1 Henceforth we will use the term "propointing" to refer to standard pointing and to distinguish it from the more unusual task of "antipointing", at which one has to point to the mirror-position of a presented visual target.
} 
spatial deficit in neglect affects primarily a spatial map which is reliant on ventral stream input and which is used for perceptual or non-automatic, indirect visuomotor tasks.

In this study, we wish to examine an alternative account for these findings. Contrary to the perception-action model, we assume that perceptual tasks and also the different types of visuomotor tasks have access to the same visuospatial information (Schenk, 2010; Schenk \& Mclntosh, 2010). Please note that this assumption does not imply the existence of one unitary spatial representation, but merely the assertion that access to the potentially multiple spatial maps is not restricted to just one class of behavioural functions. To explain why propointing is spared but antipointing is impaired, we assume that visual feedback, i.e. the ability to see the moving hand during the manual action, is more useful during pro- than antipointing. A differential use of visual feedback in proand antipointing tasks could result in the observed dissociation in performance between pro- and antipointing for neglect patients if it was found that neglect patients had to rely more on visual feedback for accurate pointing performance than control participants.

Furthermore, there is a second issue with the account offered by the perception-action model. It is assumed that the need to use allocentric information turns the antipointing task into a task that is reliant on ventral stream input. But is the antipointing task used in Rossit et al. (2011) really an allocentric task? The instructions for the antipointing tasks did not mention a specific reference axis relative to which the mirroring of the target location should be carried out. As no visual reference was provided it can be assumed that participants used their own body-midline as a reference to compute the mirror position. If this is the case, antipointing is possibly better characterised as a task that requires the transposition of the target position in relation to an egocentric reference (i.e. 
for the desired end-position of the movement a new position is chosen that is at the same relative distance to the body-midline but in the opposite hemispace) rather than an allocentric task (i.e. a task where the reference for computing the relative distance of the visual target is a position in the external visual world, e.g. the centre of the computer monitor). Based on this interpretation it becomes clear that the participants' perception of their own body-midline or ego-centre might play an important role in their computation of the target location for the antipointing movement. This is of importance as it is well known that impairment in egocentric spatial perception is a deficit often found in unilateral neglect (Karnath, 1994; Karnath \& Rorden, 2012). Patients show deviations of head and gaze orientation (Fruhmann-Berger \& Karnath, 2005; Fruhmann Berger, Pross, Ilg, \& Karnath, 2006) and a bias in their perceived straight ahead direction (Karnath, 1994) towards the ipsilesional side. Karnath and his colleagues argued that this deficit might account for many of the other neglect symptoms, e.g. neglecting of contralesional objects, orienting toward the ipsilesional side when addressed from the contralesional side, and the preferential exploration of ipsilesional space during target search (Karnath, 1994; Karnath \& Rorden, 2012). It should be stressed that not all neglect-symptoms are egocentric in nature. Object-centred or allocentric deficits have also been observed but these deficits typically occur not independent of but in combination with the more prevalent egocentric deficits (see Rorden et al., 2012; Yue, Song, Huo, \& Wang, 2012)

The egocentric nature of some of the neglect symptoms might therefore also explain why neglect patients make larger errors in antipointing than in propointing (see also Dassonville, Bridgeman, Kaur Bala, Thiem, \& Sampanes, 2004; for a similar argument in relation to the differential effect of visual illusions on pro- versus antipointing). Hence, it 
is important to examine the role of the reference that is used to compute the target location in the antipointing task.

In this study, we will examine the role of visual feedback in pro- and antipointing and the effect of providing an external visual reference line for the antipointing task in patients with neglect, right-brain damaged patients without neglect and in a group of healthy participants. We predict that for all participants visual feedback is more useful for propointing as compared to antipointing. We also predict that when no visual feedback is available, neglect patients will show significantly larger errors than control participants and that the provision of visual feedback will allow neglect patients to correct their performance to the level of patients without neglect and healthy participants. We also expect that the provision of an external visual reference line will improve antipointing performance in neglect patients. Furthermore, in line with our assumption that antipointing without a visual reference line relies on an egocentric reference, we also expect that the extent to which patients benefit from the introduction of a reference line will correlate with signs of egocentric neglect.

\section{Materials and Methods}

\subsection{Participants}

Twenty patients with right-hemispheric brain damage after stroke and left visuospatial neglect (RBD+: 13 male, 7 female; mean age 64.6, SD = 12.0) according to standard clinical neglect tests (see below), were recruited for the study. In addition, twenty-three patients with right-hemispheric brain damage after stroke without left visuospatial 
neglect (RBD-: 13 male, 10 female; mean age $65.8, S D=11.7$ ) were recruited as patient control group. Table 1 shows the demographic and clinical data of the patients. Mean time since lesion onset was $39(S D=47)$ days for neglect patients and $28(S D=29)$ days for control patients and did not differ between groups $(t(40)=0.967, p=.339)$. Twenty-two healthy individuals (13 male, 9 female) served as neurologically intact control group. Their mean age was 70.9 years $(S D=6.2)$ and they had no neurological or psychiatric disorders and no movement restrictions of the upper limbs. All participants had normal or corrected-to-normal vision (Okulus, No 47211) and were right handed by self-report (i.e. all participants indicated that they use their right hand when throwing, cutting with scissors, or tooth brushing), except for two patients who were ambidextrous. Groups did not differ with regard to age $(F(2,62)=2.297, p=.109)$, or gender $\left(\operatorname{chi}^{2}(2)=\right.$ $.332, p=.847)$.

The protocol was in accord with the Declaration of Helsinki II and was approved by the ethics committee of the Friedrich-Alexander University Erlangen-Nuremberg. Prior to the investigation, participants gave their written informed consent. 
Table 1: Demographic and clinical data of right-brain-damaged patients with neglect (RBD+) and without neglect (RBD-).

\begin{tabular}{|c|c|c|c|c|c|c|c|c|c|c|c|c|c|}
\hline Group & $\begin{array}{l}\text { Patient } \\
\text { no. }\end{array}$ & $\begin{array}{l}\text { Age, } \\
\text { sex }\end{array}$ & Etiology & Lesion location & $\begin{array}{l}\text { Days } \\
\text { since } \\
\text { lesion }\end{array}$ & $\begin{array}{l}\text { Motor } \\
\text { Deficit } \\
\text { (left) }\end{array}$ & $\begin{array}{l}\text { Visual } \\
\text { field } \\
\text { defect }^{*}\end{array}$ & $\begin{array}{l}\text { Line } \\
\text { bisection } \\
-/+\mathrm{mm}\end{array}$ & $\begin{array}{l}\text { Star } \\
\text { cancellation, } \\
\text { omissions } \\
\text { L/R, max. } \\
(27 / 27)\end{array}$ & $\begin{array}{l}\text { Ota's task, } \\
\text { intact } \\
\text { circles, } \\
\text { omission } \\
\text { L/R, max. } \\
(10 / 10)\end{array}$ & $\begin{array}{l}\text { Ota's task, } \\
\text { defect circles, } \\
\text { omissions gap } \\
\text { on the left/ } \\
\text { right, max. } \\
(20 / 20)\end{array}$ & $\begin{array}{l}\text { Figure } \\
\text { copy, } \\
\text { L/R }\end{array}$ & CoC \\
\hline \multirow[t]{11}{*}{ RBD+ } & 1 & $62, \mathrm{~m}$ & I & Parietal & 57 & No & No & -7 & $0 / 0$ & $3 / 2$ & $0 / 0$ & $+/+$ & .039 \\
\hline & 2 & $59, \mathrm{~m}$ & I & $\begin{array}{l}\text { MCA territory } \\
\text { (junction of } \\
\text { anterior and } \\
\text { medial part, } \\
\text { posterior part) }\end{array}$ & 4 & HPL & No & 43 & $27 / 20$ & $10 / 4$ & $14 / 14$ & $-/+$ & .848 \\
\hline & 3 & $\begin{array}{l}62, \\
m\end{array}$ & I & Posterior & 3 & No & $\mathrm{L}-\mathrm{HH}$ & 15 & $27 / 11$ & $10 / 0$ & $14 / 12$ & $+/+$ & .612 \\
\hline & 4 & $\begin{array}{l}87 \\
m\end{array}$ & I & $\begin{array}{l}\text { Temporal- } \\
\text { parietal }\end{array}$ & 3 & No & No & 30 & $27 / 10$ & $10 / 6$ & $4 / 3$ & $-/+$ & .652 \\
\hline & 5 & $59, \mathrm{~m}$ & I & $\begin{array}{l}\text { MCA territory } \\
\text { (medial, } \\
\text { posterior part) }\end{array}$ & 2 & No & $\mathrm{L}-\mathrm{HH}$ & 7 & $7 / 2$ & $1 / 0$ & $3 / 0$ & $+/+$ & .054 \\
\hline & 6 & $75, \mathrm{~m}$ & I & $\begin{array}{l}\text { MCA territory } \\
\text { (medial part) }\end{array}$ & 4 & No & $\begin{array}{l}\text { Superio } \\
r \\
\text { restricti } \\
\text { on due } \\
\text { to } \\
\text { eyelid }\end{array}$ & 6 & $1 / 1$ & $1 / 0$ & $0 / 0$ & $+/+$ & .008 \\
\hline & 7 & $52, f$ & I & $\begin{array}{l}\text { MCA territory } \\
\text { (anterior part) }\end{array}$ & 2 & $\mathrm{HP}$ & No & 22 & $2 / 2$ & $4 / 0$ & $2 / 2$ & $+/+$ & .084 \\
\hline & 8 & $72, f$ & I & $\begin{array}{l}\text { Basal ganglia, } \\
\text { occipital }\end{array}$ & 6 & No & $\begin{array}{l}\text { Lateral } \\
\text { restricti } \\
\text { ons } \\
\text { bilateral }\end{array}$ & 9 & $27 / 10$ & $10 / 3$ & $11 / 10$ & $-/+$ & .746 \\
\hline & 9 & $76, \mathrm{~m}$ & I & $\begin{array}{l}\text { MCA territory } \\
\text { (medial part) }\end{array}$ & 48 & $\mathrm{HP}$ & No & 26,3 & $8 / 2$ & $4 / 0$ & $7 / 8$ & $-/+$ & .175 \\
\hline & 10 & $34, \mathrm{~m}$ & $\mathrm{H}$ & Temporal & 185 & $\mathrm{HP}$ & No & $-2,3$ & $0 / 0$ & $0 / 0$ & $2 / 1$ & $-/+$ & .000 \\
\hline & 11 & $59, f$ & I & Frontal-parietal & 45 & HPL & No & 4 & $0 / 0$ & $0 / 0$ & $0 / 0$ & $+/+$ & .000 \\
\hline
\end{tabular}




\begin{tabular}{|c|c|c|c|c|c|c|c|c|c|c|c|c|}
\hline 12 & $58, f$ & I & Basal ganglia & 18 & $\mathrm{HP}$ & No & 5,3 & $4 / 2$ & $1 / 0$ & $1 / 0$ & t/+ & .035 \\
\hline 13 & $60, \mathrm{~m}$ & $\mathrm{H}$ & Basal ganglia & 35 & $\mathrm{HP}$ & L-HH & 11,6 & $1 / 2$ & $1 / 1$ & $2 / 1$ & +/+ & .002 \\
\hline 14 & $75, f$ & I & $\begin{array}{l}\text { Parietal, } \\
\text { posterior }\end{array}$ & 28 & $\mathrm{HP}$ & No & 79,7 & $27 / 17$ & $10 / 7$ & $17 / 16$ & $-/+$ & .883 \\
\hline 15 & $76, f$ & I & $\begin{array}{l}\text { MCA territory } \\
\text { (anterior and } \\
\text { medial part) }\end{array}$ & 19 & $\mathrm{HP}$ & No & 19,6 & $27 / 19$ & $10 / 8$ & $17 / 17$ & $-/+$ & .868 \\
\hline 16 & $61, f$ & 1 & $\begin{array}{l}\text { Frontal- } \\
\text { temporal, basal } \\
\text { ganglia }\end{array}$ & 123 & $\mathrm{HP}$ & No & $-1,7$ & $2 / 1$ & $4 / 0$ & $2 / 1$ & +/+ & .093 \\
\hline 17 & $72, \mathrm{~m}$ & $\mathrm{H}$ & $\begin{array}{l}\text { Basal ganglia, } \\
\text { internal/external } \\
\text { capsule }\end{array}$ & 12 & $\mathrm{HP}$ & No & 10 & $0 / 2$ & $2 / 0$ & $5 / 4$ & +/+ & .043 \\
\hline 18 & $49, m$ & I & MCA territory & 84 & HPL & No & 2 & $3 / 0$ & $2 / 1$ & $1 / 2$ & +/+ & .051 \\
\hline 19 & $76, \mathrm{~m}$ & I & Basal ganglia & 64 & $\mathrm{HP}$ & No & 10 & $2 / 1$ & $0 / 0$ & $0 / 0$ & +/+ & .008 \\
\hline 20 & $68, m$ & $\mathrm{H}$ & $\begin{array}{l}\text { Basal ganglia, } \\
\text { external capsule }\end{array}$ & 43 & $\mathrm{HP}$ & No & 8 & $4 / 0$ & $0 / 0$ & $0 / 0$ & +/t & .015 \\
\hline Mean & 64.6 & & & 39.25 & & & 14.88 & & & & & .261 \\
\hline
\end{tabular}

\begin{tabular}{|c|c|c|c|c|c|c|c|c|c|c|c|c|c|}
\hline \multirow[t]{7}{*}{ RBD- } & 21 & $83, \mathrm{~m}$ & $\mathrm{H}$ & Basal ganglia & 5 & $\mathrm{HP}$ & No & -14 & $4 / 7$ & $1 / 2$ & $4 / 2$ & $+/+$ & -.058 \\
\hline & 22 & $59, m$ & I & $\begin{array}{l}\text { MCA territory } \\
\text { (anterior part), } \\
\text { precentral }\end{array}$ & 1 & No & No & -7 & $0 / 0$ & $0 / 0$ & $0 / 0$ & $+/+$ & .000 \\
\hline & 23 & $51, f$ & I & Thalamus & 139 & No & No & 1 & $0 / 0$ & $0 / 0$ & $0 / 0$ & +/+ & .000 \\
\hline & 24 & $45, f$ & I & Posterior & 5 & No & L-LQ & 18 & $0 / 0$ & $1 / 0$ & $1 / 0$ & +/+ & .027 \\
\hline & 25 & $65, m$ & I & Basal ganglia & 10 & No & No & 2 & $0 / 0$ & $0 / 0$ & $0 / 0$ & +/+ & .000 \\
\hline & 26 & $73, \mathrm{~m}$ & I & $\begin{array}{l}\text { MCA territory } \\
\text { (posterior part) }\end{array}$ & 2 & HP & No & 4 & $11 / 9$ & $1 / 0$ & $0 / 0$ & $+/+$ & .082 \\
\hline & 27 & $51, \mathrm{~m}$ & 1 & MCA territory & 3 & No & No & -2 & $0 / 1$ & $0 / 0$ & $0 / 0$ & $+/+$ & -.007 \\
\hline
\end{tabular}




\begin{tabular}{|c|c|c|c|c|c|c|c|c|c|c|c|c|}
\hline 28 & $60, f$ & I & Pericentral & 26 & No & No & $-3,6$ & $1 / 2$ & $2 / 0$ & $0 / 0$ & $+/+$ & .001 \\
\hline 29 & $75, \mathrm{~m}$ & I & Posterior & 21 & No & No & -4 & $0 / 2$ & $0 / 0$ & $0 / 0$ & $+/+$ & -.008 \\
\hline 30 & $54, f$ & $\mathrm{H}$ & temporal & 31 & No & No & 1,6 & $0 / 0$ & $0 / 0$ & $0 / 0$ & $+/+$ & .000 \\
\hline 31 & $85, f$ & I & $\begin{array}{l}\text { Temporal, } \\
\text { parietal }\end{array}$ & 29 & No & No & -5 & $0 / 0$ & $0 / 1$ & $3 / 0$ & $+/+$ & -.010 \\
\hline 32 & $46, \mathrm{~m}$ & I & Parietal & 30 & No & No & $-5,3$ & $0 / 1$ & $0 / 0$ & $0 / 0$ & $+/+$ & -.002 \\
\hline 33 & $76, f$ & I & $\begin{array}{l}\text { MCA territory } \\
\text { (posterior part) }\end{array}$ & 24 & No & No & -5 & $0 / 0$ & $0 / 0$ & $0 / 1$ & $+/+$ & -.006 \\
\hline 34 & $73, f$ & $\mathrm{H}$ & Basal ganglia & 18 & HP & No & 1 & $0 / 0$ & $1 / 0$ & $0 / 1$ & $+/+$ & .020 \\
\hline 35 & $50, f$ & $\mathrm{H}$ & Frontal-parietal & 34 & HPL & No & 2,67 & $0 / 0$ & $0 / 0$ & $0 / 0$ & $+/+$ & .000 \\
\hline 36 & $62, f$ & I & $\begin{array}{l}\text { Parietal, } \\
\text { posterior }\end{array}$ & 22 & No & No & 4,6 & $0 / 2$ & $1 / 0$ & $0 / 0$ & $+/+$ & .021 \\
\hline 37 & $75, \mathrm{~m}$ & I & & 18 & & No & 6,6 & $0 / 0$ & $0 / 1$ & $0 / 0$ & $+/+$ & -.074 \\
\hline 38 & $73, \mathrm{~m}$ & I & $\begin{array}{l}\text { Frontal-parietal, } \\
\text { insular cortex }\end{array}$ & 21 & No & No & -2 & $1 / 1$ & $1 / 0$ & $1 / 0$ & $+/+$ & .016 \\
\hline 39 & $71, \mathrm{~m}$ & I & $\begin{array}{l}\text { Lentiform } \\
\text { nucleus, internal } \\
\text { capsule }\end{array}$ & 66 & HPL & No & 3 & $0 / 2$ & $0 / 0$ & $1 / 0$ & $+/+$ & -.010 \\
\hline 40 & $70, f$ & I & $\begin{array}{l}\text { Frontal-parietal, } \\
\text { insular cortex }\end{array}$ & 43 & No & No & -5 & $0 / 1$ & $0 / 0$ & $0 / 0$ & $+/+$ & -.010 \\
\hline 41 & $73, m$ & I & $\begin{array}{l}\text { Lentiform } \\
\text { nucleus }\end{array}$ & 21 & HP & No & 4,3 & $1 / 2$ & $0 / 0$ & $0 / 0$ & $+/+$ & .000 \\
\hline 42 & $69, m$ & I & $\begin{array}{l}\text { Temporal, } \\
\text { occipital }\end{array}$ & 32 & No & No & 1,6 & $1 / 1$ & $0 / 0$ & $0 / 0$ & $+/+$ & -.005 \\
\hline 43 & $75, m$ & $\mathrm{H}$ & Basal ganglia & 37 & & No & $-3,3$ & $1 / 0$ & $0 / 1$ & $0 / 1$ & $+/+$ & -.007 \\
\hline
\end{tabular}


Notes: ${ }^{\star}$ The diagnosis of visual field defects was based on a clinical examination by a neurologist. Abbreviations: $\mathrm{m}$ : male; f: female; I: infarct, $\mathrm{H}$ : haemorrhage; MCA: middle cerebral artery ; HP: hemiparesis; HPL: hemiplegia; L-HH: left homonymous hemianopia; L-LQ: lower left homonymous quadrantanopia; Neglect tests: L: left; $M=$ middle, $R$ = right; Figure Copy: -- = omissions or distortions; + = normal performance; Line Bisection: + = rightward deviation; - = leftward deviation; CoC: Center of Cancellation. 


\subsection{Clinical tests}

Five common paper-and-pencil tests for the assessment of visuospatial neglect were conducted: Line bisection, star cancellation and copy drawing of the NET (Neglect test [Fels \& Geissner, 1996], the German version of the Behavioural Inattention Test [BIT; Wilson, Cockburn, \& Halligan, 1987]) and the Ota's circle task (Ota, Fujii, Suzuki, Fukatsu \& Yamadori, 2001), which was performed twice, first with the instruction of cancelling all intact circles and a second time with the instruction of cancelling all circles with a gap, as proposed by Rorden et al. (2012). To be considered impaired in the star cancellation task and the Ota's intact circle task patients had to show a minimum of two omissions on the left side and the number of omissions on the left side had to exceed those on the right side. In the line bisection task, patients showing a mean rightward deviation of more than $5 \mathrm{~mm}$ were considered to be impaired. In the drawing task, distortions or omissions on the left side of copied objects were counted as errors. Patients showing any errors were considered to be impaired in this task. Finally, to be considered impaired in the second version of the Ota task (finding the circles with a gap), patients had to neglect at least two circles with left-sided gaps and the number of neglected circles with left-sided gaps had to exceed the number of neglected circles with right-sided gaps. A patient was assigned to the neglect group when she/he showed impaired performance in at least two of the five neglect tests. To prevent the inclusion of patients with residual neglect in the control patient group, patients who despite scoring below our cut-off showed neglect-like behaviour, like starting to explore test sheets from the right side, whose relatives report neglect-like behaviour and whose clinical record contained the diagnosis of neglect were also included in the neglect group. This was the case for four patients (\#1,6,11, 19, see Table 1). Please note that the reassignment of 
these patients did not affect the findings (i.e. the same findings were obtained when those four patients were excluded from the analysis). For two of the four patients (\# 6,19) data on another neglect test (TAP neglect [Zimmermann \& Fimm, 2009]) was available. In this task, patients sat in front of a computer monitor. Approximately 20 digits were presented on the monitor distributed in a random spatial pattern across the computer monitor. Occasionally, a target stimulus flashed at unpredictable temporal intervals and on unpredictable spatial locations. The target stimulus consisted of a stream of rapidly changing digits. Patients were instructed to press a response button as soon as the target stimulus was detected. Both patients failed to respond to target stimuli presented on the left much more frequently than to target stimuli presented on the right half of the computer monitor. Given that most classical neglect tests do not impose a time limit, it is perhaps not surprising to find patients who on classical tests perform within the normal range but show clear signs of neglect in tests that are timesensitive (Bonato \& Deouell, 2013).

To have a continuous measure of egocentric neglect severity the Center-of-Cancellation (CoC) measure as introduced by Rorden \& Karnath (2010) was computed. Our CoC measure was based on the performance in the star cancellation and Ota's circle task (i.e. the egocentric version with the instruction of cancelling all intact circles). The final value of our $\mathrm{CoC}$ variable corresponds to the average $\mathrm{CoC}$ of both tasks. Scores vary between -1 (only left most item is cancelled) and +1 (only right most item is cancelled). When all targets are cancelled by a patient, the CoC is 0 . 


\subsection{Setup}

The propointing and antipointing tasks were programmed in E-prime 2 (Psychology Software Tools, Inc., Pittsburgh, PA) and presented on a 24" computer monitor, using a screen resolution of $1024 \times 768$ pixel. The monitor was covered with an add-on touch screen (Magic touch USB 5, Keytec Inc., Garland, Texas) and connected to a notebook. End-positions were recorded with one pixel accuracy, corresponding to a spatial resolution of $0.52 \mathrm{~mm}$ for the horizontal axis and $0.39 \mathrm{~mm}$ for the vertical axis. LCShutter glasses (PLATO, Translucent, Toronto, CA) were used to manipulate the availability of visual feedback. A customised response-box was used to measure the onset of the pointing response and the release-signal from the start button was used to control the LC-shutter glasses. In the no-feedback condition, the shutter glasses switched from translucent to opaque as soon as participants released the start button to initiate their pointing response. Each participant was individually tested in a quiet and darkened room. Participants were seated in front of the touch screen with their head placed on a head-chin rest. The distance between eyes and screen was $56 \mathrm{~cm}$. To prevent patients from using the monitor's edges as spatial cues a torus-shaped black cardboard covered those edges.

\subsection{Tasks}

Two different propointing tasks and four different antipointing tasks were conducted. Figure 1 illustrates the different tasks and Table 2 summarizes the relevant parameters. The target stimulus was a grey cross (width: $12 \mathrm{~mm}$; height: $16 \mathrm{~mm}$; stroke width: $1 \mathrm{~mm}$ ) 
against a black background presented randomly at one of six different positions (see Figure 2).

Six practice trials (each trial presented the target at a different position) in conditions 1 , 5, and 6 (see Table 2) and 12 practice trials (with only 6 different target positions to choose from each target position was used twice) in the conditions 2, 3, 4, 7, 8 (Table 2) preceded 60 experimental trials (10 per target position). Trials were presented in a randomised sequence.

The general procedure for each propointing and antipointing task was as follows: The participant pressed the start button on the response box with her/his right index finger and the cross appeared on the screen. A tone signalled the initiation of a pointing response. Participants were instructed to touch the required location on the screen as quickly and accurately as possible. Another tone indicated that the screen had been successfully touched. In the antipointing tasks without reference line, participants were required to point to the mirror location of the target in the opposite hemispace. To keep the instruction similar to those of Rossit et al., (2011), we did not mention a specific reference axis relative to which the mirroring of the target location should be carried out, but merely told them to point to the mirror position of the visual target in the opposite hemispace. If asked directly by the participants, we informed them that hemispace was defined relative to their body-midline. In the antipointing tasks with reference line, participants were instructed to point to the position that was at the mirror-position relative to the presented reference line (grey vertical line, $31 \mathrm{~mm}$ long and $1 \mathrm{~mm}$ wide); the lines were presented to the left or right of the crosses. There were three different positions of the reference line along the $x$-axis: reference line 1: $80 \mathrm{~mm}$ left of the centre of the 
screen; reference line 2:in the centre; reference line 3: $80 \mathrm{~mm}$ right of the centre. By varying the position of the reference line, we could examine whether participants could compute the relative distance between target stimulus and a visual landmark (the reference line) and use this relative (allocentric) spatial information to determine the required end position for their pointing response. It was hypothesized that the specific problems of neglect patients with antipointing might reflect their specific inability to use allocentric information (Rossit et al., 2011). In contrast, we suggest that it might be an egocentric bias in neglect that is in part responsible for their difficulties in antipointing. The two alternative accounts produce contrasting predictions for our study. The allocentric-deficit account suggests that for neglect patients the problems in antipointing become worse when a visual reference line of varying position is used. In contrast, the egocentric-deficit account predicts that performance of neglect patients improves with the availability of a visual reference line even if that reference line varies in position. The cross positions and reference lines were combined in such a way that there were ten trials with each reference line and a cross presented to the right of the reference line and ten trials with each reference line and a cross presented to the left of the reference line.

There were three different sequences of conditions (see Table 3) varied within each group. Conditions with a reference line were always presented after the conditions without a reference line to ensure that the positions of the visual reference lines did not influence the performance in the conditions without reference line. 
Table 2: Parameters for the different tasks

\begin{tabular}{|c|c|c|}
\hline Task & Condition & Description \\
\hline \multirow[t]{2}{*}{ Propointing } & 1. Closed loop (CL) & Shutter glasses open (see Fig. 1A) \\
\hline & 2. Open loop (OL) & Shutter glasses closed after button release (see Fig. 1B) \\
\hline \multirow[t]{4}{*}{ Antipointing } & 3. With feedback with reference line & Shutter glasses open; reference line (see Fig. 1D) \\
\hline & 4. With feedback without reference line & Shutter glasses open; no reference line (see Fig. 1C) \\
\hline & 5. Without feedback with reference line & Shutter glasses closed after button release; reference line \\
\hline & 6. Without feedback without reference line & Shutter glasses closed after button release; no reference line \\
\hline
\end{tabular}

Table 3: Sequences of conditions

\begin{tabular}{lll}
\hline Sequence A & Sequence B & Sequence C \\
\hline 1. Propointing with feedback & 1. Antipointing with feedback without ref. & 1. Propointing without feedback \\
2. Propointing without feedback & 2. Antipointing without feedback without ref. & 2. Propointing with feedback \\
3. Antipointing with feedback without ref. & 3. Propointing with feedback & 3. Antipointing without feedback without ref. \\
4. Antipointing without feedback without ref. & 4. Propointint without feedback & 4. Antipointing withfeedback without ref. \\
5. Antipointing with feedback with ref. & 5. Antipointing with feedback with ref. & 5. Antipointing without feedback with ref. \\
6. Antipointing without feedback with ref. & 6. Antipointing without feedback with ref. & 6. Antipointing with feedback with ref.
\end{tabular}

Abbreviation: ref.: reference line. 


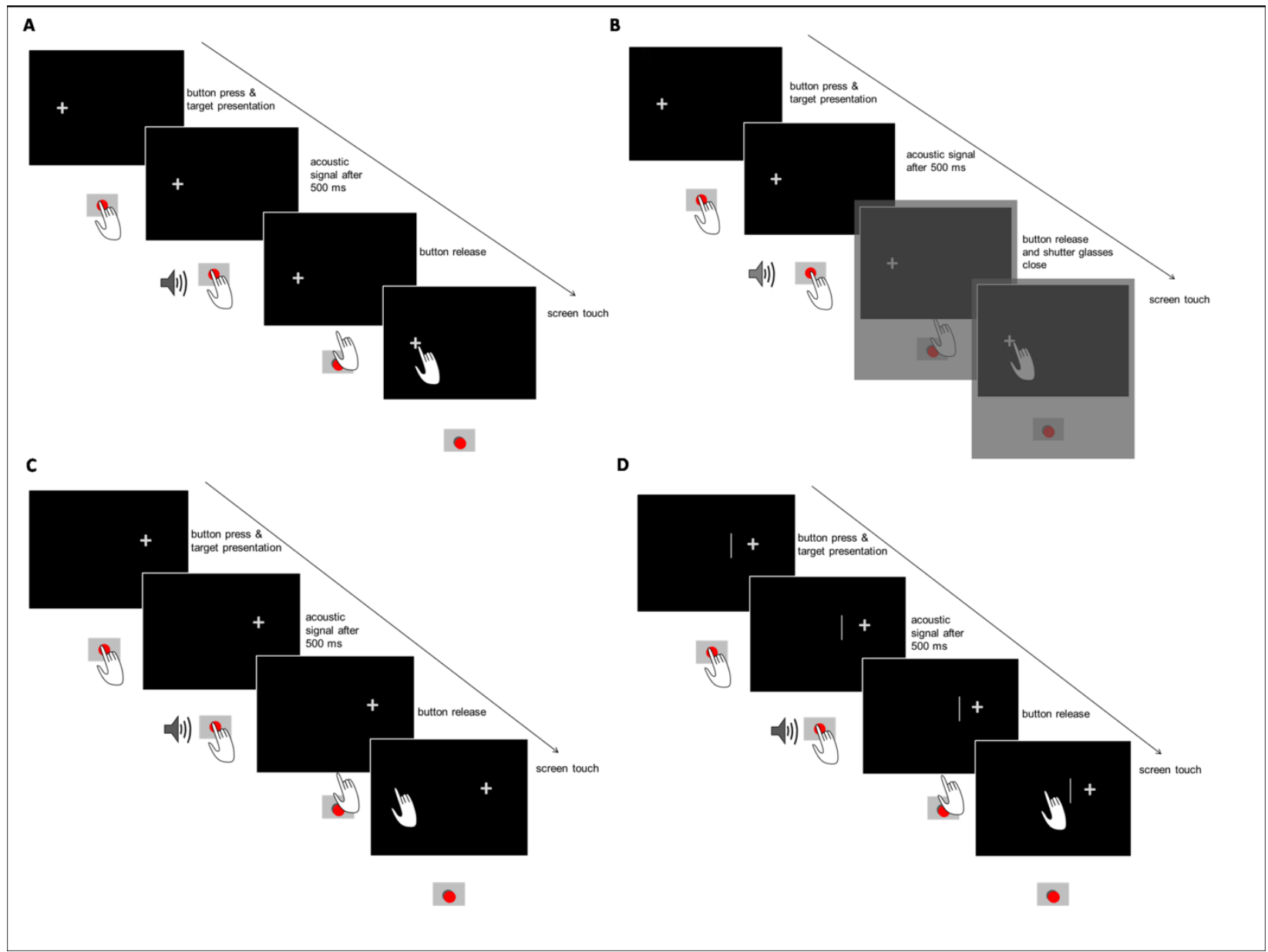

Figure 1: Illustration of the pointing tasks. A: propointing with feedback. B: propointing without feedback. C: antipointing with feedback without reference line. D: antipointing with feedback with reference line. Note that in the versions of $C$ and $D$ without feedback (not illustrated), shutter classes close after button release (see B). Closure of shutter glasses is illustrated by a grey transparent box, in the experiment however participants' view was completely blocked such that they could neither see the screen nor their moving hand. 


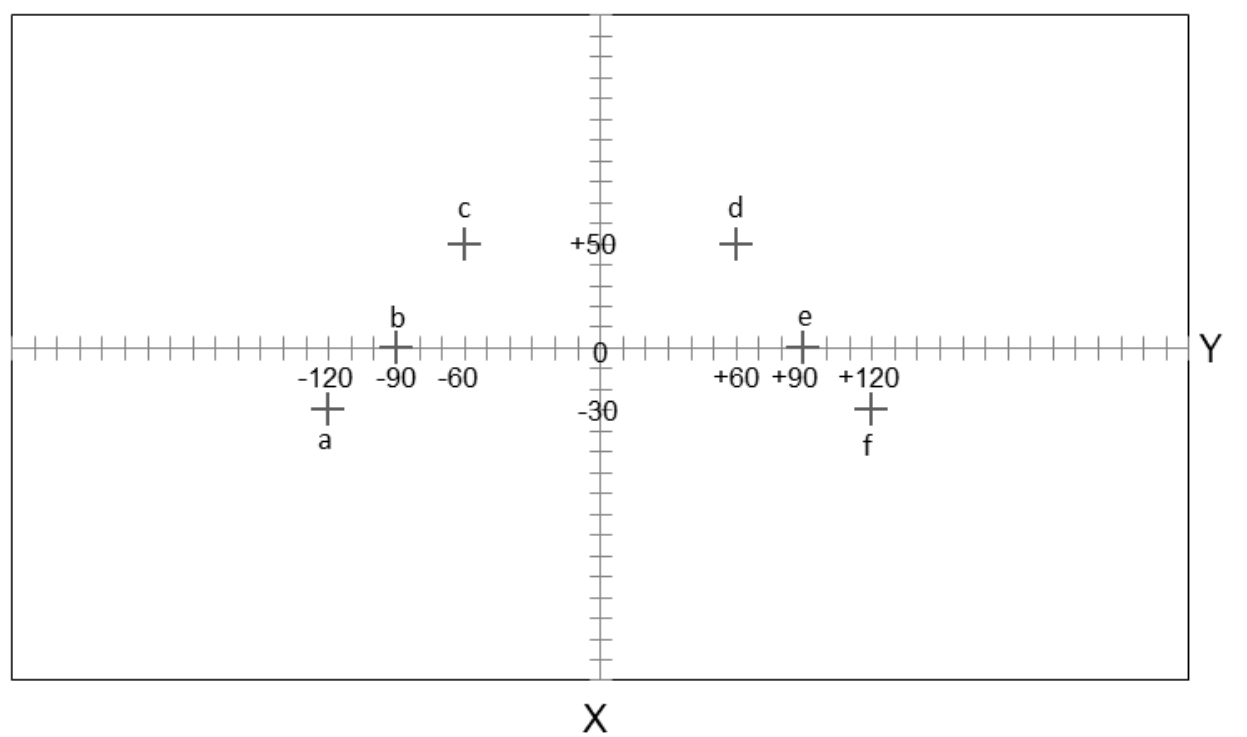

Figure 2: Illustrations of the 6 different cross locations. In each trial a cross in one of the six different positions (a-f) appeared on the screen (without the axes, letters and numbers). The coordinates of the positions were $-120 /-30$ (cross a), $-90 / 0$ (cross b), $-60 /+50$ (cross c), $+60 /+50$ (cross d), +90/0 (cross e), $+120 /-30$ (cross f) mm relative to the centre of the screen. The first value corresponds to the position along the $x$-axis; the second value corresponds to the position along the $y$-axis. Negative values correspond to positions left or below the centre $(0 / 0)$ and positive values correspond to positions right or above the centre.

\subsection{Data analysis}

The horizontal pointing error, reflecting the distance in $\mathrm{mm}$ along the horizontal axis between the end-position of the finger on the touch screen and target position, was computed for each trial. In propointing, the target position was identical with the position of the presented cross; in antipointing the target position was the mirrored position of the 
presented cross. For each participant and each propointing and antipointing task the mean absolute value of the horizontal pointing error was computed (i.e. the absolute or unsigned error). As we were interested in group differences we focused on the analysis of main effects and interactions with the factor group.

For both propointing and antipointing, we computed a "feedback effect". This feedback effect was calculated by subtracting the unsigned errors for trials with visual feedback from the errors in trials without visual feedback, and used to examine our prediction that the effect of feedback is different for pro- and antipointing. Furthermore, the effect of the reference line was examined by computing the difference between the unsigned error in antipointing trials without reference line and antipointing trials with reference line. This variable is called "reference effect".

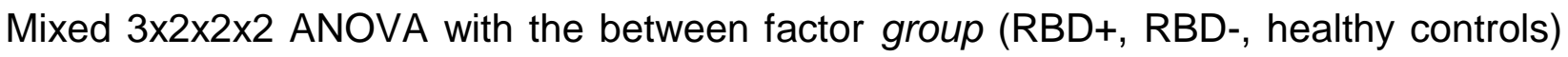
and the within factors task (propointing, antipointing without reference), feedback (without, with) and presentation side (left, right) were conducted. To break down the interactions, one-way ANOVAs with the factor group (RBD+, RBD-, healthy controls) were computed for each task. Furthermore, mixed 3x2x2 ANOVA with the between factor group (RBD+, RBD-, healthy controls) and the within factors reference line (without, with) and presentation side (left, right) was computed for the antipointing tasks without feedback. To explore the interaction effect, a one-way ANOVA with the factor group (RBD+, RBD-, healthy controls) was performed for antipointing without and with reference line separately. One-way ANOVAs were used to further explore the effects of feedback and reference line. Moreover, to test our assumption that antipointing performance without reference line is related to the severity of egocentric neglect we 
computed a Pearson correlation between the measure for the severity of egocentric neglect and the reference effect.

Where appropriate we used the Bonferroni procedure to compensate for multiple comparisons and report the corrected p-values. All analyses were computed with IBM SPSS Statistics 19 with an alpha level of $p=.05$.

\section{Results}

\subsection{Effects of feedback on propointing and antipointing (without reference line)}

\subsubsection{Unsigned error}

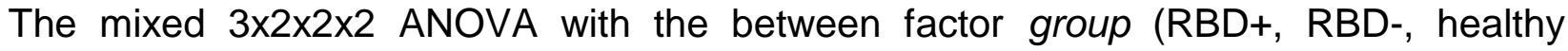
controls) and the within factors task (propointing, antipointing without reference), feedback (without, with) and presentation side (left, right) showed a significant main effect of group, $F(2,62)=18.72, p<.001$, a significant main effect of task, $F(1,62)=$ $85.74, p<.001$, as well as a significant main effect of feedback, $F(1,62)=49.52, p<$ .001. Furthermore, there were significant interaction effects between the factors group and task, $F(2,62)=8.74, p<.001$, task and feedback, $F(1,62)=28.26, p<.001$, as well as between task, feedback and group, $F(2,62)=8.80, p=.002$.

To test specifically our hypothesis that RBD+ patients will be worse compared to the other groups when feedback cannot be effectively used, we conducted one-way ANOVAs with the factor group (RBD+, RBD-, healthy controls) for each task separately. ANOVAs were corrected for multiple comparisons with the Bonferroni method. We 
predicted that RBD+ patients will perform worse than participants in the control groups for propointing without feedback and for antipointing but not for propointing with feedback. As predicted, there was a significant group effect for propointing without feedback, $F(2,62)=5.95, p=.016$, antipointing without feedback, $F(2,62)=15.45, p<$ .001 , as well as antipointing with feedback, $F(2,62)=13.29, p<.001$. The group effect for propointing with feedback was not significant, $F(2,62)=4.34, p=.068$..

Bonferroni post-hoc tests were carried out to explore significant effects obtained in the ANOVA. RBD+ patients showed significantly larger errors $(M=29.95 \mathrm{~mm}, S D=25.26$ $\mathrm{mm})$ compared to healthy individuals $(M=15.64 \mathrm{~mm}, S D=8.88 \mathrm{~mm}, p=.012)$ and RBD- patients $(M=15.63 \mathrm{~mm}, S D=6.70 \mathrm{~mm} ; p=.011)$ in propointing without feedback, whereas there were no differences between the two control groups in this task $(p>.999$; see Figure $3 \mathrm{~A}$ ). 


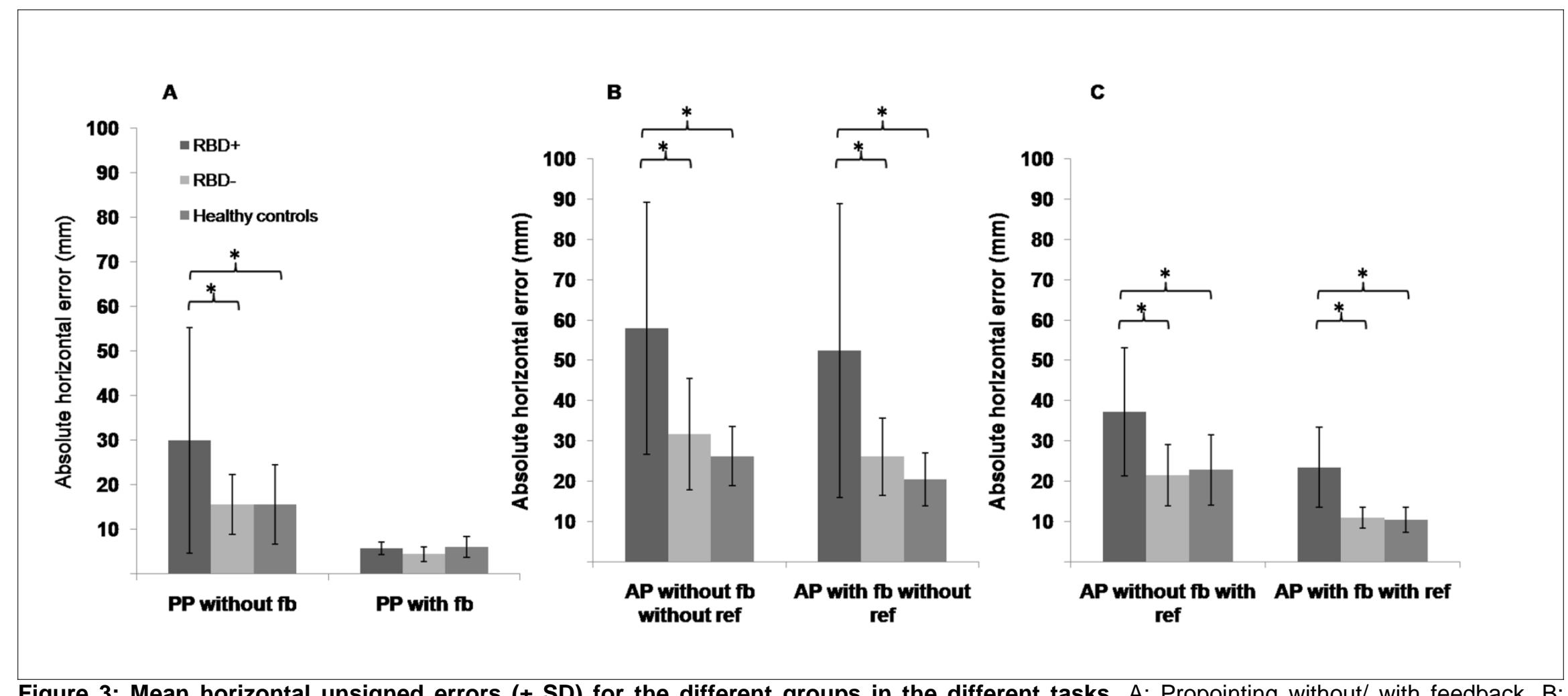

Figure 3: Mean horizontal unsigned errors ( \pm SD) for the different groups in the different tasks. A: Propointing without/ with feedback. B:

Antipointing with/ without feedback without reference line. C: Antipointing with/without feedback with reference line. Abbreviations: PP = propointing; $A P=$ antipointing; $f b=$ feedback; ref $=$ reference line. ${ }^{*}$ indicates significance. 
In antipointing with as well as without feedback, unsigned errors of RBD+ patients (without feedback: $M=57.95 \mathrm{~mm}$; $S D=31.33 \mathrm{~mm}$; with feedback: $M=52.41 \mathrm{~mm}, S D=$ $36.45 \mathrm{~mm}$ ) were significantly larger compared to those of healthy participants (without feedback: $M=26.21 \mathrm{~mm} ; S D=7.34 \mathrm{~mm}$; with feedback: $M=20.44 \mathrm{~mm}, S D=6.59 \mathrm{~mm}$ ) and RBD- controls (without feedback: $M=31.67 \mathrm{~mm} ; S D=13.77 \mathrm{~mm}$; with feedback: $M$ $=26.06 \mathrm{~mm}, S D=9.57 \mathrm{~mm}$; all $p>.05$; see Figure $3 \mathrm{~B}$ ). In the antipointing task, the two control groups did not differ in their unsigned errors: this was true for both feedback and no feedback condition (both $p>$.999).

To further examine the effect of feedback, we computed the feedback effect that is the difference in unsigned errors between feedback and no feedback conditions for the respective tasks (propointing, antipointing). The feedback effect was used as the dependent measure in a dependent t-test with the factor task and a one-way ANOVA with the factor group. The feedback effect for propointing $(M=28.26 \mathrm{~mm} ; S D=31.91$ $\mathrm{mm}$ ) was significantly larger compared to antipointing $(M=10.89 \mathrm{~mm} ; S D=22.40 \mathrm{~mm})$, $t(64)=4.718, p<.001$. Furthermore, a significant group effect was found for propointing, $F(2,62)=5.563, p=.006$, but not antipointing, $F(2,62)=0.002, p=.998$.

RBD+ patients differed significantly from healthy participants $(p=.01)$ and RBD-controls $(p=.023)$, whereas no differences were found between the two control groups $(p>.999$; see Figure 4), meaning that the withdrawal of feedback in propointing had a more pronounced effect in neglect patients compared to healthy individuals and patients without neglect.

One reviewer asked us to employ non-parametric tests as there is substantial interindividual variability in our data that violates the assumptions of the ANOVA. Using 
Kruskal-Wallis and Mann-Whitney $U$ tests, we obtained the same results as with the parametric tests, except for the propointing with feedback condition. RBD- patients showed larger unsigned errors compared to RBD+ patients and healthy controls $(p<$ .05). Importantly, however, also with non-parametric tests, RBD+ patients did not differ significantly from healthy controls in propointing with feedback $(p=.80)$.

To sum up, the withdrawal of feedback has a stronger effect on propointing compared to antipointing and this effect is more pronounced in neglect patients than in any of the other groups.

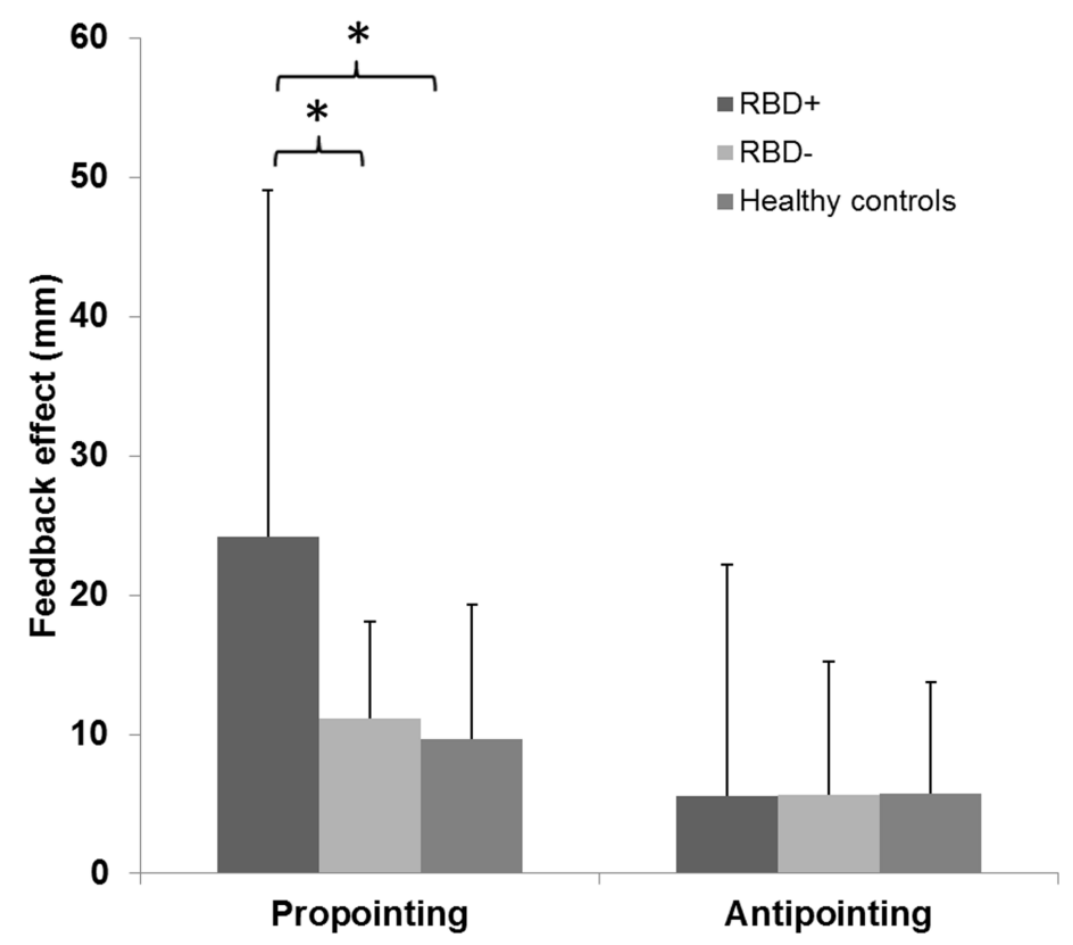

Figure 4: Feedback effect $( \pm S D)$ for the different groups in propointing and antipointing. The feedback effect is the difference of unsigned errors between the condition without and the condition with feedback. *indicates significance.

\subsubsection{Directional error}


The aim of our study was to examine an alternative account for the task-specific deficits of patients with neglect in antipointing. For directional errors, Rossit and colleagues (2011) did not report task-specific effects. We, therefore, restricted our original analysis to unsigned errors. However, one reviewer asked us to also present our findings on

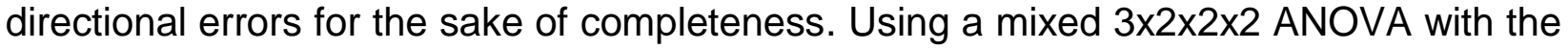
between factor group [RBD+, RBD-, healthy controls] and the within factors task [propointing, antipointing without reference], feedback [without, with] and presentation side [left, right] we performed a global analysis of the direction error. In the absence of a specific hypothesis or specific predictions, no further post-hoc tests were carried out. The four-way ANOVA revealed a significant main effect of feedback, $F(2,62)=4.354, p$ $<.041$ and a significant interaction between task and side, $F(1,62)=7.156, p=.01$. Furthermore, there was a significant three-way interaction between feedback, presentation side and group, $F(2,62) 3.918, p=.025$, as well as between task, feedback and presentation side, $F(1,62)=28.76, p<.001$. The other effects were not significant (all $p>.05$ ). Table 4 shows the mean directional errors for the different tasks, presentation sides and groups. A look at this table (relevant for the analysis: first 8 columns) suggests that feedback effects were most pronounced for the group of neglect patients but those effects were modulated by task and hemifield. The feedback effects were more pronounced for targets presented to the right hemifield. Descriptively, feedback in propointing reduced the error as expected, feedback in antipointing, if anything, increased the error. 
Table 4: Mean directional errors (SD) in $\mathrm{mm}$ for the different tasks and different presentation sides of the crosses

\begin{tabular}{|c|c|c|c|c|c|c|c|c|c|c|}
\hline & $\begin{array}{l}\text { PP } \\
\text { with fb } \\
\text { - left }\end{array}$ & $\begin{array}{l}\text { PP } \\
\text { with fb } \\
\text { - right }\end{array}$ & $\begin{array}{l}\text { PP } \\
\text { without } \\
\text { fb - left }\end{array}$ & $\begin{array}{l}\text { PP } \\
\text { without } \\
\text { fb - } \\
\text { right }\end{array}$ & $\begin{array}{l}\text { AP with } \\
\text { fb } \\
\text { without } \\
\text { ref - left }\end{array}$ & $\begin{array}{l}\text { AP } \\
\text { with fb } \\
\text { without } \\
\text { ref - } \\
\text { right }\end{array}$ & $\begin{array}{l}\text { AP } \\
\text { without } \\
\text { fb } \\
\text { without } \\
\text { ref - left }\end{array}$ & $\begin{array}{l}\text { AP } \\
\text { without } \\
\text { fb } \\
\text { without } \\
\text { ref - } \\
\text { right }\end{array}$ & $\begin{array}{l}\text { AP } \\
\text { without } \\
\text { fb with } \\
\text { ref - } \\
\text { left }\end{array}$ & $\begin{array}{l}\text { AP } \\
\text { without } \\
\text { fb with } \\
\text { ref - } \\
\text { right }\end{array}$ \\
\hline $\mathrm{HC}$ & $\begin{array}{l}16.18 \\
(6.77)\end{array}$ & $\begin{array}{l}-2.59 \\
(5.63)\end{array}$ & $\begin{array}{l}0.05 \\
(37.34)\end{array}$ & $\begin{array}{l}7.45 \\
(31.02)\end{array}$ & $\begin{array}{l}-24.77 \\
(27.08)\end{array}$ & $\begin{array}{l}19.95 \\
(35.24)\end{array}$ & $\begin{array}{l}-29.05 \\
(33.97)\end{array}$ & $\begin{array}{l}1.45 \\
(50.58)\end{array}$ & $\begin{array}{l}28.14 \\
(35.01)\end{array}$ & $\begin{array}{l}-12.55 \\
(42.79)\end{array}$ \\
\hline RBD+ & $\begin{array}{l}6.05 \\
(9.54)\end{array}$ & $\begin{array}{l}-9.15 \\
(5.34)\end{array}$ & $\begin{array}{l}-14.55 \\
(81.01)\end{array}$ & $\begin{array}{l}-28.65 \\
(58.60)\end{array}$ & $\begin{array}{l}-55.55 \\
(134.53)\end{array}$ & $\begin{array}{l}36.15 \\
(81.78)\end{array}$ & $\begin{array}{l}-45.40 \\
(119.08)\end{array}$ & $\begin{array}{l}-5.70 \\
(119.69)\end{array}$ & $\begin{array}{l}-13.77 \\
(49.07)\end{array}$ & $\begin{array}{l}-14.78 \\
(85.92)\end{array}$ \\
\hline RBD- & $\begin{array}{l}3.22 \\
(5.52)\end{array}$ & $\begin{array}{l}-8.43 \\
(4.99)\end{array}$ & $\begin{array}{l}-12.83 \\
(31.63)\end{array}$ & $\begin{array}{l}-2.57 \\
(28.89)\end{array}$ & $\begin{array}{l}-10.87 \\
(42.25)\end{array}$ & $\begin{array}{l}0.83 \\
(38.83)\end{array}$ & $\begin{array}{l}-0.61 \\
(53.35)\end{array}$ & $\begin{array}{l}-17.22 \\
(54.06)\end{array}$ & $\begin{array}{l}14.45 \\
(38.92)\end{array}$ & $\begin{array}{l}-22.60 \\
(33.95\end{array}$ \\
\hline
\end{tabular}

Notes: a negative value denotes a leftward horizontal deviation from the target position; a positive value indicates a rightward horizontal deviation from the target position. Left denotes a cross position on the left side of the screen; right denotes a cross position on the right side of the screen. Abbreviations: AP: antipointing; fb: feedback; HC: healthy individuals; PP: propointing; RBD+: right brain-damaged patients with neglect; RBD-: right brain-damaged patients without neglect; ref: reference line.

; RBD-: right brain-damaged patients without neglect; ref: reference line.

\subsection{Effects of a reference line on antipointing}

\subsubsection{Unsigned error}

A mixed 3x2x2 ANOVA with the between factor group (RBD+, RBD-, healthy controls) and the within factors reference line (without, with) and presentation side (left, right) for the antipointing tasks without feedback was conducted. This analysis showed a significant main effect of group, $F(1,57)=16.95, p<.001$, a significant main effect of 
reference line, $F(1,57)=18.12, p<.001$, and a significant interaction between group and reference line, $F(2,57)=3.18, p<.001$. To explore this interaction effect a one-way ANOVA with the factor group (RBD+, RBD-, healthy controls) was conducted for antipointing with reference line. Note that, the results for the one-way ANOVA for antipointing without reference line (without feedback) were already reported in the previous section (Effects of feedback on propointing and antipointing; see Figure $3 \mathrm{~B}$ ). In this section, we focus on the effect of group in antipointing when a reference line was provided.

There was a significant main effect of group in antipointing with reference line, $F(2,57)=$ 15.45, $p<.001$. RBD+ patients showed larger unsigned errors $(M=37.18 \mathrm{~mm}, S D=$ $15.95 \mathrm{~mm})$ than RBD- patients $(M=21.49 \mathrm{~mm}, S D=7.76 \mathrm{~mm} ; p<001)$ and healthy individuals $(M=22.82 \mathrm{~mm}, S D=8.73 \mathrm{~mm} ; p<.001)$, whereas RBD- patients did not significantly differ from healthy individuals ( $p>.999$; see Figure $3 \mathrm{C})$.

Similar to the previous section investigating the feedback effect, the reference effect was determined by computing the difference between unsigned error in antipointing without reference line (without feedback) and antipointing with reference line (without feedback). A one-way ANOVA with reference effect as dependent measure and the factor group was conducted. There was a significant group effect, $F(1,57)=3.178, p=.049$.

The reference effect was significantly larger for RBD+ patients $(M=34.22 ; S D=91.91)$ compared to healthy individuals $(M=6.55 ; S D=17.66, p=.045$; see Figure 5), but only numerically larger compared to RBD- patients $(M=16.65 ; S D=29.30, \mathrm{p}=.374)$. The reference effect did also not differ significantly between the two control groups $(p>.999)$ 
In summary, the introduction of a reference line reduced the unsigned error in antipointing and this effect was more pronounced in patients with neglect as compared to healthy individuals, but only quantitatively so compared to patients without neglect.

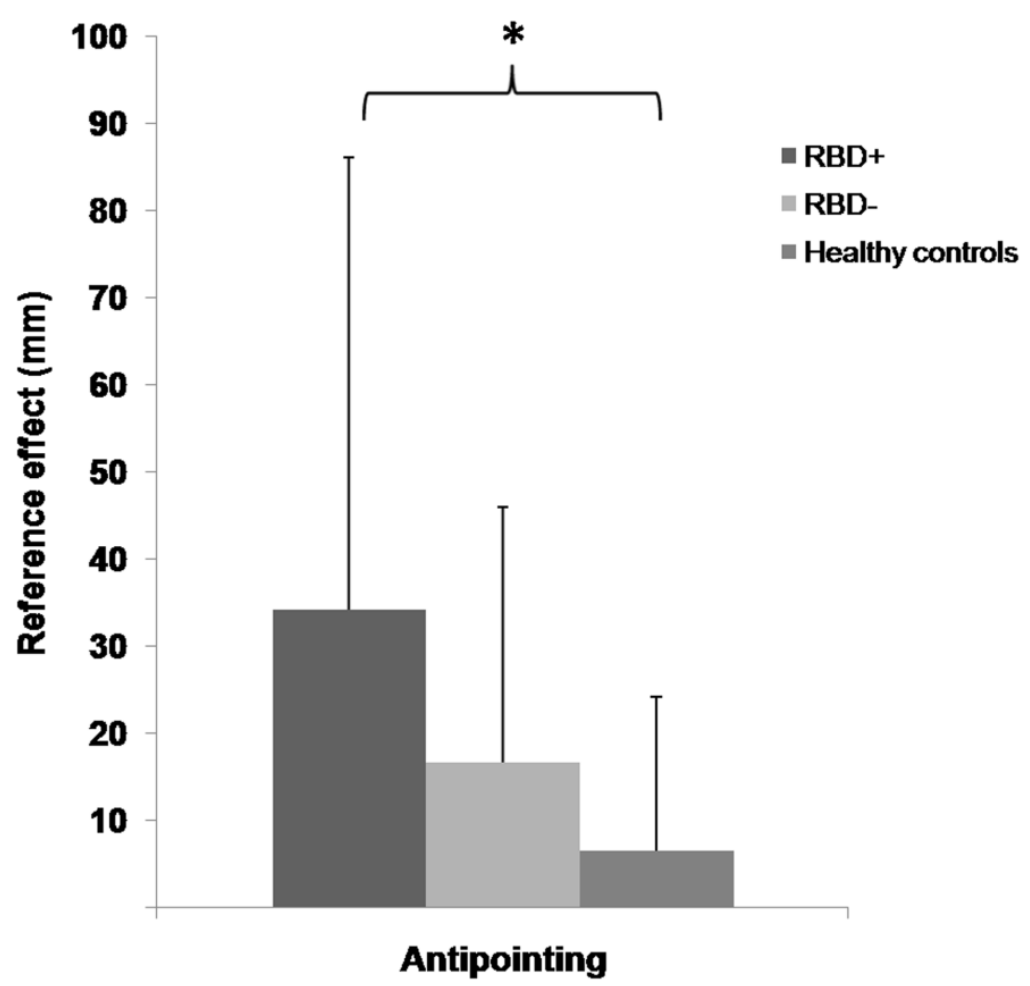

Figure 5: Reference effect ( \pm SD) for the different groups in antipointing. The reference effect is the difference of unsigned errors between antipointing without and antipointing with reference line. *indicates significance.

One of the reviewers suggested to test our hypothesis more directly. We claim that the difference between antipointing and propointing disappears when a reference line is provided and visual feedback is withdrawn. This prediction could be tested by computing the difference between two tasks (antipointing with reference line but without feedback and propointing without feedback) and examining whether this difference is similar in all 
three groups. When using a one-way ANOVA no significant group effect emerged $(F(2,59)=0.006, p=.994)$. The same results were obtained when non-parametric tests were used. These findings support our claim that the difference between the tasks (antipointing versus propointing) disappears when the effect of the egocentric bias and the effects of visual feedback are removed.

\subsubsection{Directional error}

The mixed 3×2x2 ANOVA with the between factor group (RBD+, RBD-, healthy controls) and the within factors reference line (without, with) and presentation side (left, right) for the antipointing tasks without feedback showed a significant main effect of reference line, $F(1,57)=4.413, p<.04$, and a significant interaction between reference line and side, $F(1,57)=10.312, p<.002$. Table 4 shows the mean directional errors for the different tasks, presentation sides and groups (last 4 columns are relevant for this analysis). A look at the data confirms that introduction of a reference line changed the magnitude and sign of the directional error. The type of changed induced by the reference line varied for targets on the left versus targets on the right of the reference 
line. Since the factor group produced neither a main effect nor any interaction effects (all $p>.05)$, no further analysis was carried out.

\subsection{Correlation with egocentric neglect}

To test our assumption that antipointing performance without a reference line is related to the severity of egocentric neglect, we computed the correlation between the egocentric neglect score $(\mathrm{CoC})$ and the size of the reference effect. A moderate significant correlation was obtained, $r=.401 ; p=.001$, meaning patients who suffered from a more severe form of egocentric neglect benefited more strongly from the presence of a reference line.

\section{Discussion}

In the present study, we examined whether the different role that visual feedback plays in propointing versus antipointing might explain why neglect patients perform poorly in antipointing but usually achieve normal results in propointing tasks. We argued that this 
account is only convincing if it can be shown that visual feedback is more effective for propointing than for antipointing, and if it can also be shown that neglect patients rely more strongly on visual feedback than control participants. Both predictions were confirmed by our findings when unsigned errors were analysed. The withdrawal of visual feedback had a stronger effect on propointing than on antipointing. Moreover, the feedback effect in propointing was more pronounced for neglect patients than for rightbrain damaged patients without neglect or healthy controls. We also tested how the presence of a visual reference line affects performance in the antipointing task. As predicted, the presence of a reference line did indeed reduce errors in antipointing performance and patients with a strong egocentric neglect seemed to benefit more from the presence of an external reference. However, this trend could not be confirmed when comparing patients with and patients without neglect. Nevertheless, our contention that poor antipointing performance in neglect patients could also reflect egocentric perceptual deficits, presumably due to the well-established body-midline bias found in neglect patients received some support from our findings. Specifically, we found a significant correlation between the strength of the neglect patients' egocentric bias and the extent to which they benefited from the introduction of a visual reference in the antipointing task. Unfortunately we did not have the opportunity to test midline bias directly and thus were unable to test the correlation between midline bias and the extent to which patients benefited from the provision of an external reference line.

To summarise so far, we replicated the previously described dissociation between the performance in propointing and antipointing tasks in patients with neglect. However, our findings indicate that this dissociation can be well explained by the different role that visual feedback plays in pro-and antipointing tasks and should therefore not be taken as 
evidence for the claim that the spatial deficit in neglect affects only one specific spatial map, i.e. the map which underlies perceptual judgments and non-automatic, indirect visuomotor tasks ${ }^{2}$ (Milner \& Goodale, 1995, 2006). Yet, we should also point out that one of our findings is in conflict with previous reports. In our study, we observed that neglect patients are significantly worse in propointing than control participants when visual feedback is withdrawn. Neither Himmelbach and Karnath (2003) nor Rossit, et al. (2009) found such a neglect-specific deficit when they compared reaching performance without visual feedback between patients with and without neglect. It might be tempting to argue that these reaching deficits are not related to the neglect disorder but the consequence of damage to areas in the dorsal stream. However, this account is unlikely given the fact that those deficits were found specifically only in the group of patients suffering from neglect and not in the group of right-brain damaged patients without neglect. Moreover, although we are not able to provide lesion mapping data, we have the description of neuroradiological findings (see Table 1). These descriptions do not

2 One reviewer asked us to comment on the voxel-based lesion-behaviour mapping (VLBM) findings reported by Rossit and colleagues (2011). Rossit and colleagues examined which voxels are significantly associated with antipointing errors in the group of patients with right-brain damage (irrespective of the presence of unilateral neglect). They found some significant clusters in the temporal lobe but also in the supramarginal gyrus (parietal lobe). These findings seem to suggest that there is a specific association between temporal lobe damage and antipointing errors. In our view, the specificity of this association is doubtful. Firstly, this analysis was only carried out for antipointing errors and not for propointing errors. Secondly, performance variability in propointing was so low in their study that it seems unlikely that any associations with any voxels could have emerged. Given this state of affairs, we do not really know whether the identified voxels are specific for antipointing errors or whether the same voxels might also have been selected when a correlation with impaired propointing had been computed. Based on our findings, we conjecture that the low propointing performance variability was due to the fact that visual feedback allowed patients to correct for their errors online. Thus, we would argue that the problem of antipointing and propointing not benefitting to the same extent from the availability of visual feedback affects not only the interpretation of the behavioural dissociation but also the interpretation of the VLBM results. It is therefore doubtful whether the findings from the VLBM can explain why some patients are more impaired in antipointing than in propointing tasks. 
support the claim that dorsal-stream lesions (i.e. lesions in superior portions of the parietal cortex) were more prevalent in our RBD+ group. In fact more patients from the RBD- group were reported to have parietal lesions (six patients) than from the RBD+ group (four patients). When information about lesion location was not available, information about the affected cerebrovascular territory was often reported. Parietal lesions are mostly the consequence of infarcts in the territory of the middle cerebral artery. Such infarcts were again more prevalent in the RBD- group. The claim that dorsal-stream lesions are more prevalent in patients suffering from neglect is also not supported by large-sample studies (e.g. Karnath, Ferber, \& Himmelbach, 2001; Karnath \& Rorden, 2012). Thus, we would argue that there is currently no reason to assume that dorsal-stream lesions were more prevalent in the group of patients with neglect than in the group without neglect in our study. Apart from these anatomical considerations there is also the question of whether a dorsal-stream lesion could explain the pattern of findings that we obtained. The consequence of dorsal-stream damage is best observed in patients with optic ataxia. These patients produce substantial pointing errors similar to those of the neglect patients in our study. Yet, this is where the similarity ends. Patients with optic ataxia show these pointing deficits typically only when they are asked to fixate their eyes to one location and point to a different location in visual periphery (Borchers, Muller, Synofzik, \& Himmelbach, 2013). In contrast, the neglect patients in our study were free to move their eyes but still produced substantial pointing errors. It has also been reported that a patient with optic ataxia cannot use online visual information (such as visual feedback) effectively (Pisella et al., 2004). In contrast, the neglect patients in our study used visual feedback in a very effective way. In summary, we would argue that the hypothesis of dorsal-stream lesions being responsible for the pointing deficits of 
neglect patients is not supported by the available neuroradiological data and could in our view not explain the performance pattern found in our study.

At this point, we can only speculate why we found a significant effect of neglect on openloop propointing while earlier studies did not. Firstly, it should be noted that we not only found a neglect-specific deficit in open-loop pointing, we also demonstrated that the effect of feedback is significantly more pronounced in neglect patients than in right-brain damaged patients without neglect as well as healthy controls. Earlier studies did not directly test for such group-related differences in the efficacy of feedback. Our study is also the largest study of its kind with 20 neglect patients, 23 right-brain damaged patients without neglect and 22 healthy participants. This comparatively large sample size provided us with better statistical power and thereby improved our chances to detect small to medium-sized effects. There is, in our view, also the danger of missing subtle signs of neglect when it is solely diagnosed on the basis of classical paper-andpencil tests. Such patients will then be assigned to the control patient group, thereby blurring the lines between neglect and non-neglect performance. We tried to avoid this problem in our study. We used behavioural observation as well as a time-sensitive, computerised test in addition to paper-and-pencil tests to decide whether a patient should be assigned to the neglect or the non-neglect group. Thus, while there may be good reasons for why a neglect-specific pointing deficit was found in our study but not in others, it is also clear that this finding requires confirmation from future studies. Further studies should also include data from voxel-based lesion-symptom mapping to corroborate the behavioural results. Unfortunately, we are unable to provide such an analysis, because brain-imaging data was unavailable for many of our patients. 
Our findings have both methodological and theoretical implications. We have demonstrated that visual feedback is less informative and thus less beneficial for antipointing than for propointing. Furthermore, we could show that this difference can account for the performance difference found for neglect patients in those two behavioural tasks. Thus, we would argue that performance differences between pro- and antipointing should not necessarily be interpreted as evidence that these two tasks recruit distinct neural pathways. In fact, there is fMRI evidence suggesting that pro- and antipointing involve the same regions in the dorsal part of the visual cortex (Connolly, Andersen, \& Goodale, 2003). These findings also underscore the importance of taking into account not only the availability of sensory feedback when contrasting behavioural tasks but also its informational value and thus its usefulness for a given task. It was previously demonstrated that the availability of sensory feedback (e.g. visual or haptic feedback) in one task but not the other can explain for example why illusions may have little effect on immediate grasping but a significant effect on delayed grasping (Franz, Hesse, \& Kollath, 2009) or why ventral stream damage may impair the patient's ability to perform a pantomime grasp but preserve her ability for grasping real objects (Schenk, 2012). From those demonstrations one may have concluded that it might be easily possible to avoid the confounding influence of sensory feedback by ensuring that sensory feedback is available for both of the tasks that are to be contrasted. However, our findings suggest that this strategy does not always work because sensory feedback may be more beneficial in one of the two tasks. It may therefore be a better strategy to equalize task conditions by removing the relevant sensory feedback altogether.

Apart from those methodological considerations our findings carry some theoretical implications. By providing an alternative account for the pointing-vs.-antipointing 
dissociation found in neglect patients, we challenge a further piece of evidence which has been used to support the perception-action model. While this evidence from the field of neglect does not play a central role in the debate about the model, it is nevertheless of some importance given that it provided one of the rare pieces of neuropsychological evidence coming from a group study and not just from a single patient. Moreover, the claim that the perception-action divide holds not just for a purely visual disorder such as visual agnosia but also for a multimodal disorder such as neglect provided support for the hypothesis that the distinction between perception and action is also relevant for non-visual sensory modalities (see also: Dijkerman \& de Haan, 2007). In addition, the findings by Rossit et al. (2011) supported a new characterization of the disorder of unilateral neglect, namely it introduced the idea that neglect is a deficit that affects only one specific spatial map, i.e. the map which underlies perceptual judgments and nonautomatic, indirect visuomotor tasks. Our findings challenge this characterisation of neglect and thereby undermine a view of neglect which to anybody who witnessed neglect patients' multiple difficulties to cope with everyday life always appeared to be somewhat implausible.

\section{Acknowledgements}

Kathrin S. Utz held a post-doctoral research fellowship of the Friedrich-AlexanderUniversity Erlangen-Nuremberg (program for the promotion of equal opportunities of women in science) at the time of data collection. Thomas Schenk was supported by grants from the German Research Foundation (Deutsche Forschungsgemeinschaft, DFG, grant no's: DFG-SCHE 735/2-1 and DFG-SCHE 735/3-1). 


\section{References}

Bisiach, E., \& Luzzatti, C. (1978). Unilateral neglect of representational space. Cortex, 14, 129133.

Bonato, M., \& Deouell, L. Y. (2013). Hemispatial neglect: computer-based testing allows more sensitive quantification of attentional disorders and recovery and might lead to better evaluation of rehabilitation. Front Hum Neurosci, 7, 162. doi: 10.3389/fnhum.2013.00162

Borchers, S., Muller, L., Synofzik, M., \& Himmelbach, M. (2013). Guidelines and quality measures for the diagnosis of optic ataxia. Front Hum Neurosci, 7, 324. doi: 10.3389/fnhum.2013.00324

Connolly, J. D., Andersen, R. A., \& Goodale, M. A. (2003). FMRI evidence for a 'parietal reach region' in the human brain. Experimental Brain Research. 153, 140-145.

Dassonville, P., Bridgeman, B., Kaur Bala, J., Thiem, P., \& Sampanes, A. (2004). The induced Roelofs effect: two visual systems or the shift of a single reference frame? Vision Res, 44(6), 603-611.

Dijkerman, H. C., \& de Haan, E. H. F. (2007). Somatosensory processes subserving perception and action. Behavioral and Brain Sciences, 30, 189-201. doi:http://dx.doi.org/10.1017/S0140525X07001392

Driver, J. \& P. Vuilleumier (2001). Perceptual awareness and its loss in unilateral neglect and extinction. Cognition, 79: 39-88.

Fels, M., \& Geissner, E. (1996). Neglect-Test (NET). Göttingen: Hogrefe. 
Ferber, S., \& Karnath, H. O. (1999). Parietal and occipital lobe contributions to perception of straight ahead orientation. J Neurol Neurosurg Psychiatry, 67, 572-578.

Franz, V.H., C. Hesse, \& S. Kollath, Visual illusions, delayed grasping, and memory: No shift from dorsal to ventral control (2009). Neuropsychologia, 47, 1518-1531.

Fruhmann-Berger, M., \& Karnath, H. O. (2005). Spontaneous eye and head position in patients with spatial neglect. J Neurol, 252(10), 1194-1200. doi: 10.1007/s00415-005-0831-y

Fruhmann Berger, M., Pross, R. D., Ilg, U., \& Karnath, H. O. (2006). Deviation of eyes and head in acute cerebral stroke. BMC Neurol, 6, 23. doi: 10.1186/1471-2377-6-23

Goodale, M. A., Milner, A. D., Jakobson, L. S., \& Carey, D. P. (1990). Kinematic analysis of limb movements in neuropsychological research: subtle deficits and recovery of function. Can J Psychol, 44(2), 180-195.

Harvey, M., Jackson, S. R., Newport, R., Kramer, T., Morris, D. L., \& Dow, L. (2001). Is grasping impaired in hemispatial neglect? Behav Neurol, 13(1-2), 17-28.

Harvey, M., Milner, A. D., \& Roberts, R. C. (1994). Spatial bias in visually-guided reaching and bisection following right cerebral stroke. Cortex, 30(2), 343-350.

Harvey, M., \& Rossit, S. (2012). Visuospatial neglect in action. Neuropsychologia, 50(6), 10181028. doi: 10.1016/j.neuropsychologia.2011.09.030

Heilman, K. M., Valenstein, E., \& Watson, R. T. (2000). Neglect and related disorders. Semin Neurol, 20(4), 463-470. doi: 10.1055/s-2000-13179

Himmelbach, M., \& Karnath, H. O. (2003). Goal-directed hand movements are not affected by the biased space representation in spatial neglect. Journal of Cognitive Neuroscience, 15(7), 972-980. doi: Doi 10.1162/089892903770007362 
Himmelbach, M., Karnath, H. O., \& Perenin, M. T. (2007). Action control is not affected by spatial neglect: A comment on Coulthard et al. Neuropsychologia, 45(8), 1979-1981; discussion 1982-1984. doi: 10.1016/j.neuropsychologia.2006.12.009

Jackson, S. R., Newport, R., Husain, M., Harvey, M., \& Hindle, J. V. (2000). Reaching movements may reveal the distorted topography of spatial representations after neglect. Neuropsychologia, 38(4), 500-507.

Karnath, H. O. (1994). Subjective body orientation in neglect and the interactive contribution of neck muscle proprioception and vestibular stimulation. Brain, 117, 1001-1012.

Karnath, H. O., Dick, H., \& Konczak, J. (1997). Kinematics of goal-directed arm movements in neglect: control of hand in space. Neuropsychologia, 35(4), 435-444.

Karnath, H. O., Ferber, S., \& Himmelbach, M. (2001). Spatial awareness is a function of the temporal not the posterior parietal lobe. Nature, 411(6840), 950-953. doi: $10.1038 / 35082075$

Karnath, H. O., \& Rorden, C. (2012). The anatomy of spatial neglect. Neuropsychologia, 50(6), 1010-1017. doi: 10.1016/j.neuropsychologia.2011.06.027

Kerkhoff, G. (2001). Spatial hemineglect in humans. Prog Neurobiol, 63(1), 1-27.

Konczak, J., \& Karnath, H. O. (1998). Kinematics of goal-directed arm movements in neglect: control of hand velocity. Brain Cogn, 37(3), 387-403. doi: 10.1006/brcg.1998.1004

Marshall, J. C., \& Halligan, P. W. (1988). Blindsight and insight in visuo-spatial neglect. Nature, $336,766-767$.

Maraj, A., \& Heath, M. (2010). Antipointing: perception-based visual information renders an offline mode of control. Experimental Brain Research, 202(1), 55-64. 
Mattingley, J. B., Husain, M., Rorden, C., Kennard, C., \& Driver, J. (1998). Motor role of human inferior parietal lobe revealed in unilateral neglect patients. Nature, 392(6672), 179-182. doi: $10.1038 / 32413$

Mclntosh, R. D., McClements, K. I., Dijkerman, H. C., Birchall, D., \& Milner, A. D. (2004). Preserved obstacle avoidance during reaching in patients with left visual neglect. Neuropsychologia, 42(8), 1107-1117. doi: 10.1016/j.neuropsychologia.2003.11.023

McIntosh, R. D., McClements, K.I., Schindler, I., Cassidy, T.P., Birchall, D., Milner, A.D. (2004) Avoidance of obstacles in the absence of visual awareness. Proc Biol Sci. 271(1534):1520.

Milner, A. D., \& Goodale, M. A. (1995). The visual brain in action: Oxford: Oxford University Press.

Milner, A. D., \& Goodale, M. A. (2006). The visual brain in action (2 ed.). Oxford: Oxford University Press.

Milner, A. D., \& Goodale, M. A. (2008). Two visual systems re-viewed. Neuropsychologia, 46(3), 774-785. doi: 10.1016/j.neuropsychologia.2007.10.005

Ota, H., Fujii, T., Suzuki, K., Fukatsu, R., \& Yamadori, A. (2001). Dissociation of body-centered and stimulus-centered representations in unilateral neglect. Neurology, 57(11), 20642069.

Pisella, L., Michel, C., Grea, H., Tilikete, C., Vighetto, A., \& Rossetti, Y. (2004). Preserved prism adaptation in bilateral optic ataxia: strategic versus adaptive reaction to prisms. Exp Brain Res, 156(4), 399-408. doi: 10.1007/s00221-003-1746-4 
Rorden, C., Hjaltason, H., Fillmore, P., Fridriksson, J., Kjartansson, O., Magnusdottir, S., \& Karnath, H. O. (2012). Allocentric neglect strongly associated with egocentric neglect. Neuropsychologia, 50(6), 1151-1157. doi: 10.1016/j.neuropsychologia.2012.03.031

Rorden, C., \& Karnath, H. O. (2010). A simple measure of neglect severity. Neuropsychologia, 48(9), 2758-2763. doi: 10.1016/j.neuropsychologia.2010.04.018

Ross, A.I., Schenk, T., Billino, J., Macleod, M..J., Hesse, C. (in press). Avoiding unseen obstacles: Subcortical vision is not sufficient to maintain normal obstacle avoidance behaviour during reaching. Cortex (this issue).

Rossit, S., Malhotra, P., Muir, K., Reeves, I., Duncan, G., \& Harvey, M. (2011). The role of right temporal lobe structures in off-line action: evidence from lesion-behavior mapping in stroke patients. Cereb Cortex, 21(12), 2751-2761. doi: 10.1093/cercor/bhr073

Rossit, S., Malhotra, P., Muir, K., Reeves, I., Duncan, G., Livingstone, K., . . Harvey, M. (2009). No neglect-specific deficits in reaching tasks. Cereb Cortex, 19(11), 2616-2624. doi: 10.1093/cercor/bhp016

Schenk, T. (2010). Visuomotor robustness is based on integration not segregation. Vision Res, 50(24), 2627-2632. doi: 10.1016/j.visres.2010.08.013

Schenk, T. (2012). No dissociation between perception and action in patient DF when haptic feedback is withdrawn The Journal of Neuroscience, 32(6): p. 2013-2017.

Schenk, T., \& Mclntosh, R. D. (2010). Do we have independent visual streams for perception and action? Cognitive Neuroscience, 1(1), 52-62.

Striemer, C.L., Chapman, C.S., Goodale, M.A. (2009) Real-time obstacle avoidance in the absence of primary visual cortex. Proc Natl Acad Sci USA, 106 (37):15996-6001. doi: 10.1073/pnas.0905549106. 
Wilson, B., Cockburn, J., \& Halligan, P. (1987). The Behavioural Inattention Test. Bury St. Edmunds: Thames Valley Test Company.

Yue, Y., Song, W., Huo, S., \& Wang, M. (2012). Study on the occurrence and neural bases of hemispatial neglect with different reference frames. Arch Phys Med Rehabil, 93(1), 156162. doi: $10.1016 /$ j.apmr.2011.07.192

Zimmermann, P., \& Fimm, B. (2009). Testbatterie zur Aufmerksamkeitsprüfung 2.2. Herzogenrath: Psytest. 